\title{
Sensitivity Enhancements in Lithium Titanates by Incipient Wetness Impregnation DNP NMR
}

\author{
Snædís Björgvinsdóttir, Pinelopi Moutzouri, Pierrick Berruyer, Michael A. Hope, \\ and Lyndon Emsley \\ Institut des Sciences et Ingéniere Chimiques, Ecole Polytechnique Fédérale de Lausanne (EPFL), \\ $\mathrm{CH}-1015$ Lausanne, Switzerland
}

\section{Supplementary information}

page

S2 Enhancements

S4 Sensitivity values

S5 Error estimations

S5 Estimation of spin diffusion coefficients

S6 Numerical simulations

S7 Saturation recovery relaxation measurements

S8 SEM images

S9 References 


\section{Enhancements}

Table S1. Enhancement values for $\mathrm{Li}_{2} \mathrm{TiO}_{3}$ and $\mathrm{Li}_{4} \mathrm{Ti}_{5} \mathrm{O}_{12}$ impregnated with a $16 \mathrm{mM}$ solution of TEKPol in TCE, spinning at $8 \mathrm{kHz}$ MAS and at sample temperature of $100 \mathrm{~K}$. The spectra were processed with a $100 \mathrm{~Hz}$ line broadening. The enhancements are evaluated as $\varepsilon=I_{\text {on }} / I_{\text {off, }}$ where $l$ is signal intensity. Error evaluations are explained on page $S 4$.

\begin{tabular}{l|rrr}
\hline $\mathrm{Li}_{2} \mathrm{TiO}_{3}$ & Recycle delay / s & $\varepsilon$ & $\Delta \varepsilon$ \\
\hline${ }^{1} \mathrm{H}$ echo & 4.375 & 415 & 5 \\
$\mathrm{CP}^{1} \mathrm{H}-{ }^{7} \mathrm{Li}$ & 4.375 & 99 & 2 \\
echo ${ }^{7} \mathrm{Li}$ & 81.25 & 1.6 & 0 \\
$\mathrm{CP}^{1} \mathrm{H}-{ }^{6} \mathrm{Li}$ & 4.375 & 184 & 26 \\
echo ${ }^{6} \mathrm{Li}$ & 1000 & 12 & 0.2 \\
\hline \multicolumn{4}{c}{} \\
\hline $\mathrm{Li}_{4} \mathrm{Ti}_{5} \mathrm{O}_{12}$ & Recycle delay / s & $\varepsilon$ & $\Delta \varepsilon$ \\
\hline${ }^{1} \mathrm{H}$ echo & 5 & 343 & 5 \\
$\mathrm{CP}^{1}{ }^{1}-{ }^{7} \mathrm{Li}$ & 5 & 305 & 15 \\
echo $^{7} \mathrm{Li}$ & 60 & 86 & 0.5 \\
$\mathrm{CP}^{1} \mathrm{H}-{ }^{6} \mathrm{Li}$ & 5 & 10 & 1 \\
\hline
\end{tabular}

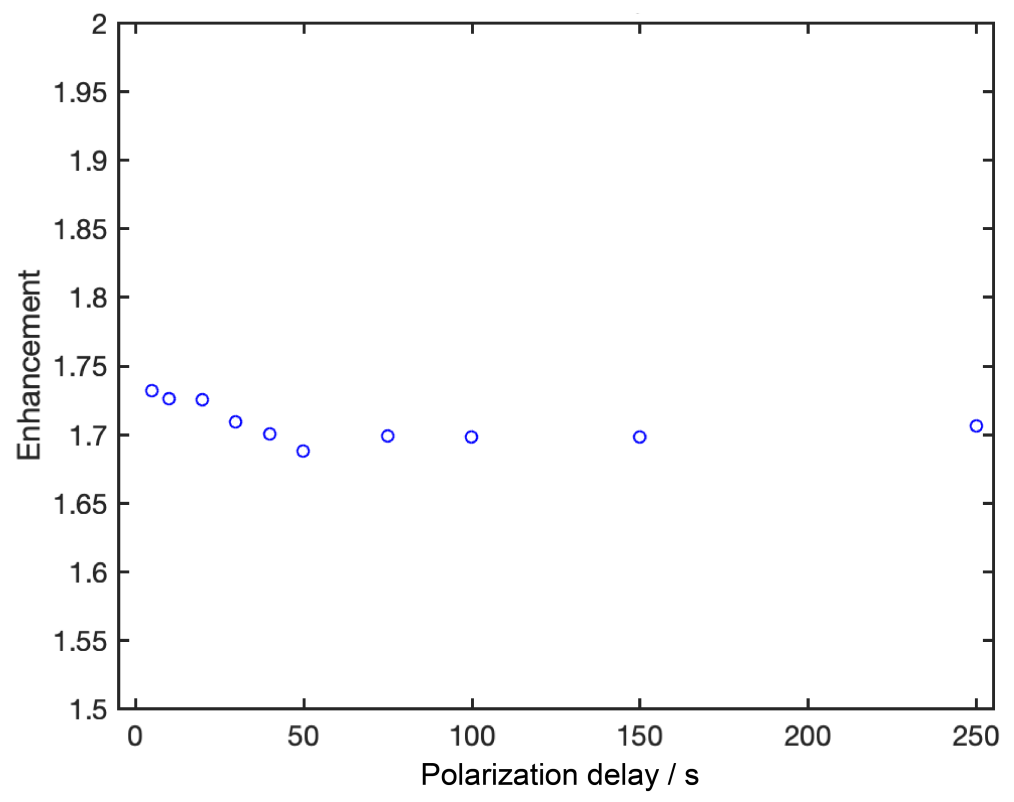

Figure S1. ${ }^{7} \mathrm{Li}$ enhancement as a function of polarization delay in $\mathrm{Li}_{2} \mathrm{TiO}_{3}$. 


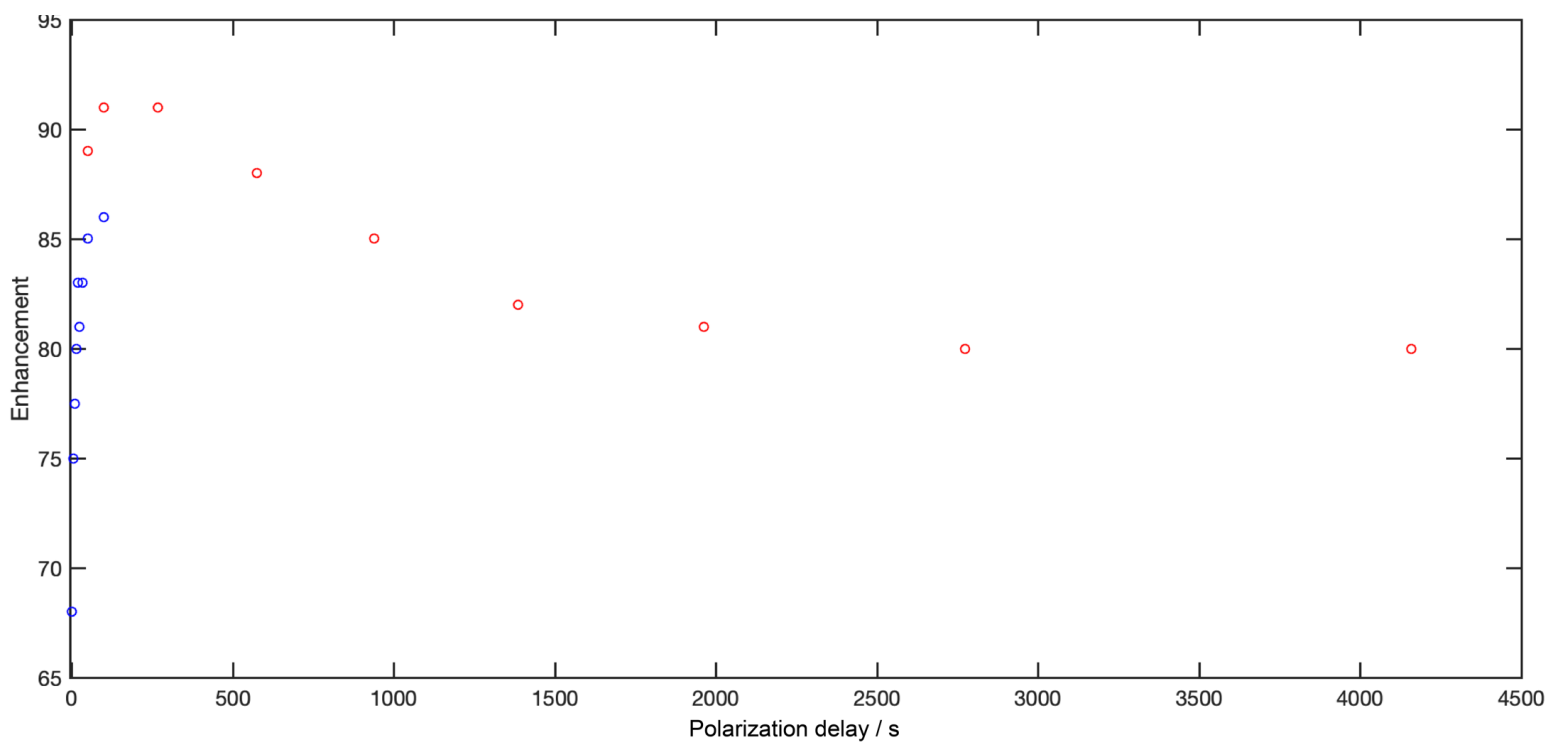

Figure S2. ${ }^{7} \mathrm{Li}$ enhancement as a function of polarization delay in $\mathrm{Li}_{4} \mathrm{Ti}_{5} \mathrm{O}_{12}$. The red and the blue dots probe different areas of the recovery curve, but since they are recorded on two different days and there are slight differences in the enhancements for the overlapping recycle delays of 50 and $100 \mathrm{~s}$. 


\section{Sensitivity values}

Table S2. Sensitivity values for $\mathrm{Li}_{2} \mathrm{TiO}_{3}$, which are displayed in the bar chart in Figure 1 . The $\mathrm{Li}_{2} \mathrm{TiO}_{3}$ powders, either neat or impregnated with a $16 \mathrm{mM}$ solution of TEKPol in TCE, were spun at $8 \mathrm{kHz}$ MAS and at sample temperature of $100 \mathrm{~K}$. When measuring signal-to-noise ratios a $200 \mathrm{~Hz}$ exponential weighting function was applied before Fourier transform to all the data. The signal-to-noise ratios reported are the mean of two $500 \mathrm{ppm}$ regions on either side of the lithium signal. Error evaluations are explained on page S4.

\begin{tabular}{ll|rrrrrr}
\hline nucleus & experiment & $\begin{array}{r}\text { Mass / } \\
\mathrm{mg}\end{array}$ & $\begin{array}{r}\text { Recycle } \\
\text { delay / }\end{array}$ & $\begin{array}{r}\text { Number } \\
\text { of scans }\end{array}$ & Exp. time / h & SNR & $\begin{array}{r}\text { Sensitivity } \\
\text { SNR/mg/vh }\end{array}$ \\
\hline $\mathbf{7 L i}$ & neat direct & 52.9 & 81.25 & 2 & 0.0451 & 4951 & 440.5 \\
& DNP direct & 36.3 & 81.25 & 2 & 0.0451 & 4035 & 523.2 \\
& DNP CP & 36.3 & 4.375 & 8 & 0.0097 & 4214 & 1177.4 \\
\hline $\mathbf{6} 6 \mathbf{L i}$ & neat direct & 52.9 & 4000 & 2 & 2.2222 & 120 & 1.5 \\
& DNP direct & 36.3 & 2300 & 2 & 1.2778 & 1078 & 26.3 \\
& DNP CP & 36.3 & 4.375 & 8 & 0.0097 & 223 & 62.3 \\
& pulse cooling & 36.3 & 600 & 2 & 0.3333 & 1780 & 85 \\
\hline
\end{tabular}

Table S3. Sensitivity values for $\mathrm{Li}_{4} \mathrm{Ti}_{5} \mathrm{O}_{12}$, which are displayed in the bar chart in Figure 2. The $\mathrm{Li}_{4} \mathrm{Ti}_{5} \mathrm{O}_{12}$ powders, either neat or impregnated with a $16 \mathrm{mM}$ solution of TEKPol in TCE, were spun at $8 \mathrm{kHz}$ MAS and at sample temperature of $\sim 100 \mathrm{~K}$. When measuring signal-to-noise ratios a $200 \mathrm{~Hz}$ exponential weighting function was applied before Fourier transform to all the data. The signal-to-noise ratios reported are the mean of two $500 \mathrm{ppm}$ regions on either side of the lithium signal. Error evaluations are explained on page S4.

\begin{tabular}{ll|rrrrrr}
\hline nucleus & experiment & $\begin{array}{r}\text { Mass / } \\
\mathrm{mg}\end{array}$ & $\begin{array}{r}\text { Recycle } \\
\text { delay / } \mathrm{s}\end{array}$ & $\begin{array}{r}\text { Number } \\
\text { of scans }\end{array}$ & Exp. time / h & SNR & $\begin{array}{r}\text { Sensitivity } \\
\text { SNR/mg/vh }\end{array}$ \\
\hline $\mathbf{7 L i}$ & neat direct & 43.8 & 1067 & 2 & 0.5928 & 4630 & 137.3 \\
& DNP direct & 30.2 & 587.5 & 2 & 0.3264 & 13090 & 758.7 \\
& DNP CP & 30.2 & 5 & 8 & 0.0111 & 7010 & 2202.1 \\
& pulse cooling & 30.2 & 300 & 2 & 0.1667 & $10048 *$ & 1630.0 \\
\hline \multirow{6}{6}{$\mathbf{L i}$} & neat direct & 43.9 & 15000 & 2 & 8.3333 & 19 & 0.15 \\
& DNP direct & 30.2 & 4159 & 2 & 2.3106 & 816 & 17.8 \\
& DNP CP & 30.2 & 5 & 4 & 0.0056 & 154 & 68.2 \\
& pulse cooling & 30.2 & 300 & 2 & 0.1667 & 406 & 33.0 \\
\hline
\end{tabular}




\section{Error estimation}

Sensitivities. For the sensitivity values reported in Figures 1 and 2, the signal-to-noise ratios of the spectra were measured in Topspin, where the noise value varies depending on the selected noise region. This can be due to baseline imperfections, correlated noise, residual signal from background or instrumental imperfections. We estimate this variability to be around $10 \%$ of the signal-to-noise ratio, and therefore add $10 \%$ error bars to each calculated sensitivity value, even if this is likely to overestimate the error for some of the sensitivities.

Enhancements. The estimation of errors on the enhancement curves in Figure 3, and the enhancements reported in Figures 1 and 2 (and Table S3), was done based on noise level.

$$
\Delta \varepsilon=\varepsilon \sqrt{\left(\frac{\Delta I_{\text {on }}}{I_{\text {on }}}\right)^{2}+\left(\frac{\Delta I_{\text {off }}}{I_{\text {off }}}\right)^{2}}
$$

Here, $\varepsilon$ is enhancement based on signal integrals, $l$ is the signal intensity with or without microwave irradiation, and $\Delta /$ is the noise value. Each curve has a fixed error value, the highest absolute error among the points on the curve, which overestimates the errors of some of the single points. ${ }^{1}$ The error bars for ${ }^{7} \mathrm{Li}$ are smaller than the data points.

\section{Estimation of spin diffusion coefficients}

Table S4. Estimated upper bounds of the dipolar couplings $d$ and the static spin diffusion coefficients $D$ for ${ }^{6} \mathrm{Li}$ and ${ }^{7} \mathrm{Li}$ in $\mathrm{Li}_{2} \mathrm{TiO}_{3}$ and $\mathrm{Li}_{4} \mathrm{Ti}_{5} \mathrm{O}_{12}$. The dipolar couplings are using $d=$ $\left(\mu_{0} h \gamma^{2}\right) /\left(4 \pi r^{3}\right)$, where $\mu_{0}$ and $h$ are constants, $\gamma$ is the gyromagnetic ratio $(16.555 \mathrm{MHz} / \mathrm{T}$ for ${ }^{7} \mathrm{Li}$ and $6.27 \mathrm{MHz} / \mathrm{T}$ for ${ }^{6} \mathrm{Li}$ ) and $r$ is the shortest $\mathrm{Li}-\mathrm{Li}$ distance in the known crystal structures $\mathrm{s}^{2-3}$. The spin diffusion coefficients are scaled from the measured $D$ for ${ }^{19} \mathrm{~F}$ in a static single-crystal of $\mathrm{CaF}_{2}\left(D=710 \mathrm{~nm}^{2} \mathrm{~s}^{-1}\right){ }^{4}$ using the scaling law $D \propto \sqrt[3]{c} \gamma_{I}^{2}$ where $c$ is the concentration of nuclei and $\gamma_{1}$ is the gyromagnetic ratio. ${ }^{5}$ The diffusion length $\sqrt{D T_{1}}$ reported is an upper limit, which is an approximation where the estimated diffusion coefficient for a static sample is used with the longitudinal relaxation, $T_{1}$ at $90 \mathrm{~K}$ and $8 \mathrm{kHz}$ MAS rate. This is an overestimate, as $D$ scales approximately $1 / v_{R}$ with $M S^{6}$ as and in addition many other factors affect the rate of spin diffusion. ${ }^{7}$

\begin{tabular}{l|rrrrrr}
\hline & $\boldsymbol{r}(\mathbf{A})$ & $\boldsymbol{d}(\mathbf{H z})$ & $\boldsymbol{c}(\mathbf{M})$ & $\boldsymbol{D}\left(\mathbf{n m}^{2} \mathbf{s}^{-1}\right)$ & $\boldsymbol{T}_{\mathbf{1}}(\mathbf{s})$ & $\sqrt{\boldsymbol{D T}} \mathbf{1}(\mathbf{n m})$ \\
\hline${ }^{7} \mathrm{Li} \mathrm{in} \mathrm{Li}_{2} \mathrm{TiO}_{3}$ & 2.8 & 862 & 28.9 & 85.8 & 70 & 77.5 \\
${ }^{6}{\mathrm{Li} \mathrm{in} \mathrm{Li}_{2} \mathrm{TiO}_{3}}^{7}{\mathrm{Li} \mathrm{in} \mathrm{Li}_{4} \mathrm{Ti}_{5} \mathrm{O}_{12}}^{2.8}$ & 124 & 2.3 & 5.3 & 4382 & 152 \\
${ }^{6} \mathrm{Li} \mathrm{in} \mathrm{Li}_{4} \mathrm{Ti}_{5} \mathrm{O}_{12}$ & 3.6 & 389 & 7.1 & 53.7 & 942 & 225 \\
\hline
\end{tabular}




\section{Numerical simulations}

Table S5. Parameters used for the simulations shown in Figure 3. The length of the target represents the size of the particles, which was assumed to be $200 \mathrm{~nm}$ (based on information from the supplier). The length of the source is the layer of lithium titanate that is directly polarized by DNP, and assumed to be much smaller than the whole target. The build-up time of the source was estimated to be short, as it is close to the radical source. The intrinsic $T_{1}$ of the target is a measured value (see Figure S4). The parameters that were varied to fit the curves, shown in bold, are the spin diffusion rate, the source enhancement and the slope of the hyperbolic tangent function describing the change in parameters at the interface of the source and the target. The percentage of quenched signal in the source, as well as the depolarization, were kept constant. The MATLAB code used for the simulations can be found at https://doi.org/10.1021/acs.jpcc.7b04438.

\begin{tabular}{|c|c|c|}
\hline parameter & ${ }^{7} \mathrm{Li}$ in $\mathrm{Li}_{4} \mathrm{Ti}_{5} \mathrm{O}_{12}$ & ${ }^{6} \mathrm{Li}$ in $\mathrm{Li}_{2} \mathrm{TiO}_{3}$ \\
\hline Length of target & $0.2 \mu \mathrm{m}$ & $0.2 \mu \mathrm{m}$ \\
\hline Length of source & $0.005 \mu \mathrm{m}$ & $0.005 \mu \mathrm{m}$ \\
\hline Source build-up time & $0.1 \mathrm{~s}$ & $0.1 \mathrm{~s}$ \\
\hline $\mathrm{T}_{1}$ of target & $940 \mathrm{~s}$ & $4400 \mathrm{~s}$ \\
\hline Spin diffusion rate & $1 \times 10^{-6} \mu \mathrm{m}^{2} \mathrm{~s}^{-1}$ & $1 \times 10^{-7} \mu \mathrm{m}^{2} \mathrm{~s}^{-1}$ \\
\hline Source enhancement & 450 & 80 \\
\hline Slope of tanh function & 400 & 400 \\
\hline Quenched signal in source & 0 & 0 \\
\hline Depolarization in source & 0.6 & 0.6 \\
\hline
\end{tabular}




\section{Saturation recovery relaxation measurements}

Longitudinal relaxation times, $T_{1}$, and polarization build-up times, $T_{\mathrm{b}}$, were measured using a saturation recovery pulse sequence. The data points were fit to a multi-exponential model in the case of ${ }^{7} \mathrm{Li}$ and to a mono-exponential recovery model in the case of ${ }^{6} \mathrm{Li}$. Even though impregnation is expected to modify the build-up behavior (specifically, it is expected to deviate from mono-exponential behavior in the case of ${ }^{6} \mathrm{Li}$ ) we have not taken that into account here to avoid over fitting, since the recovery curves for ${ }^{6} \mathrm{Li}$ have not reached steady state. The parameters extracted from the fits were used qualitatively in order to set the optimum recycle delay for the sensitivity measurements. They were also used as parameters in the numerical simulations
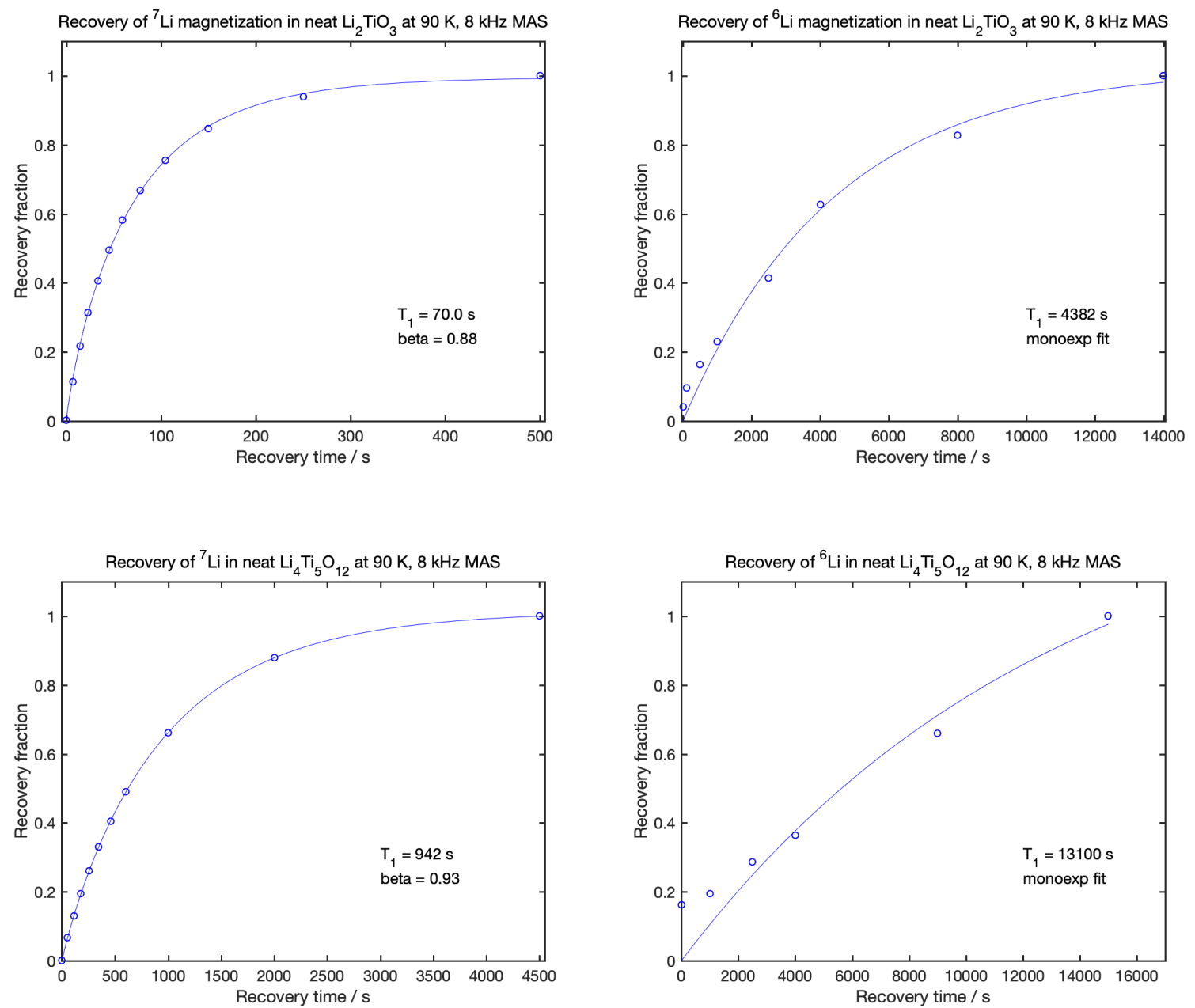

Figure S3. Recovery curves for ${ }^{6} \mathrm{Li}$ and ${ }^{7} \mathrm{Li}$ in non-impregnated samples of $\mathrm{Li}_{2} \mathrm{TiO}_{3}$ and $\mathrm{Li}_{4} \mathrm{Ti}_{5} \mathrm{O}_{12}$ spinning at $8 \mathrm{kHz}$ MAS and $90 \mathrm{~K}$. 
Table S6. Measured build-up times for ${ }^{6} \mathrm{Li}$ and ${ }^{7} \mathrm{Li}$ in impregnated samples of $\mathrm{Li}_{2} \mathrm{TiO}_{3}$ and $\mathrm{Li}_{4} \mathrm{Ti}_{5} \mathrm{O}_{12}$ spinning at $8 \mathrm{kHz}$ MAS and $90 \mathrm{~K}$.

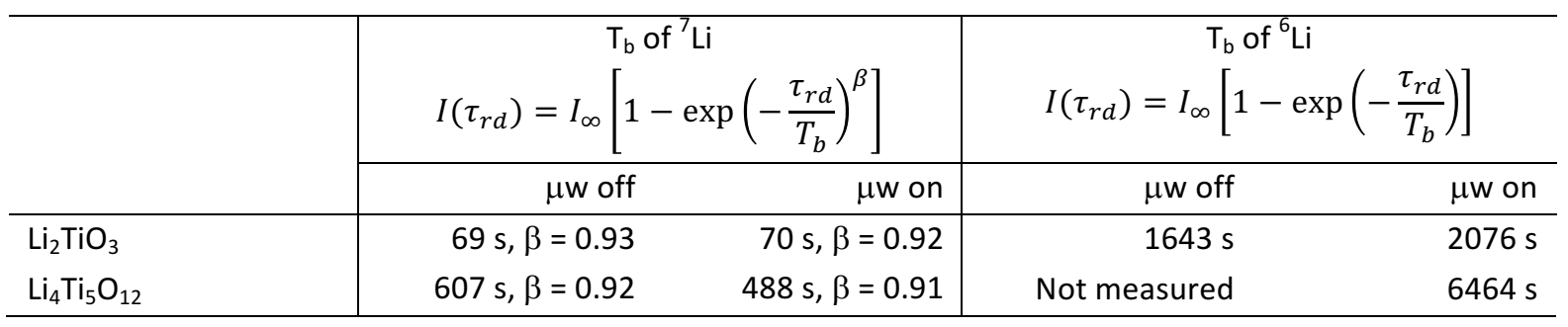

\section{SEM images}

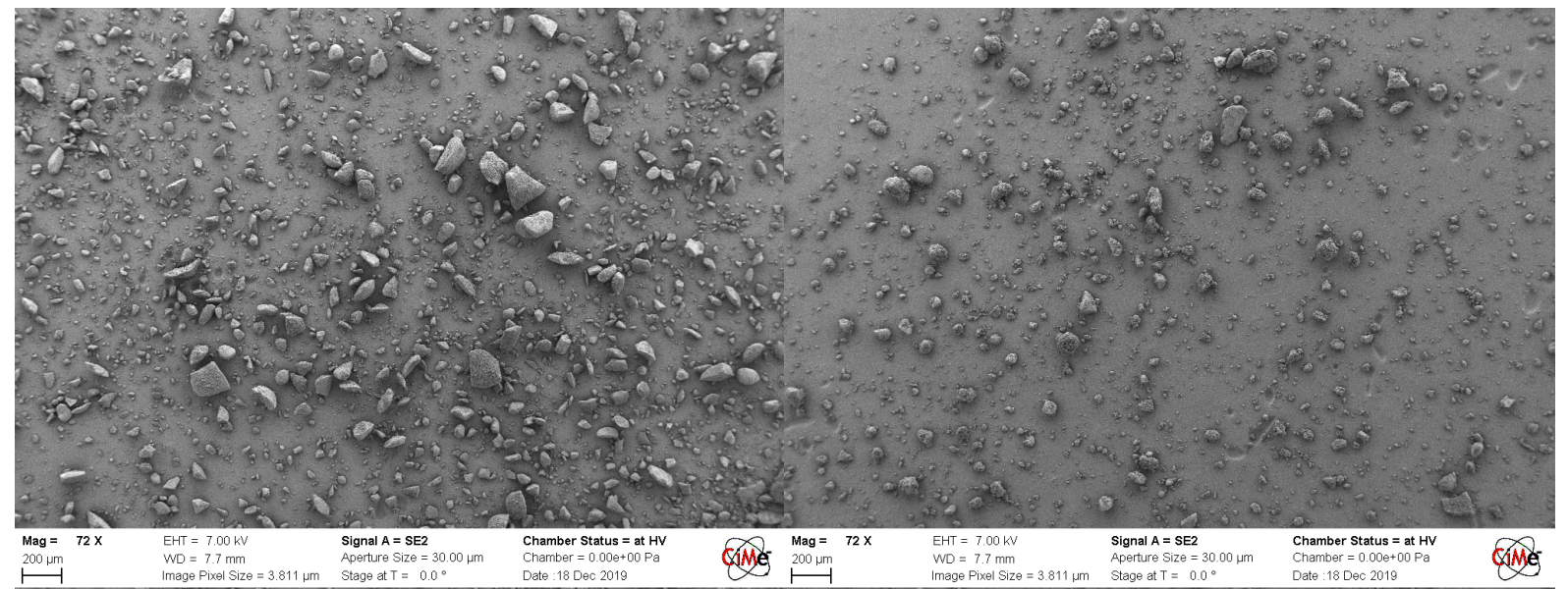

$\mathrm{Li}_{2} \mathrm{TiO}_{3}$ as received.

$\mathrm{Li}_{2} \mathrm{TiO}_{3}$ crushed by hand.

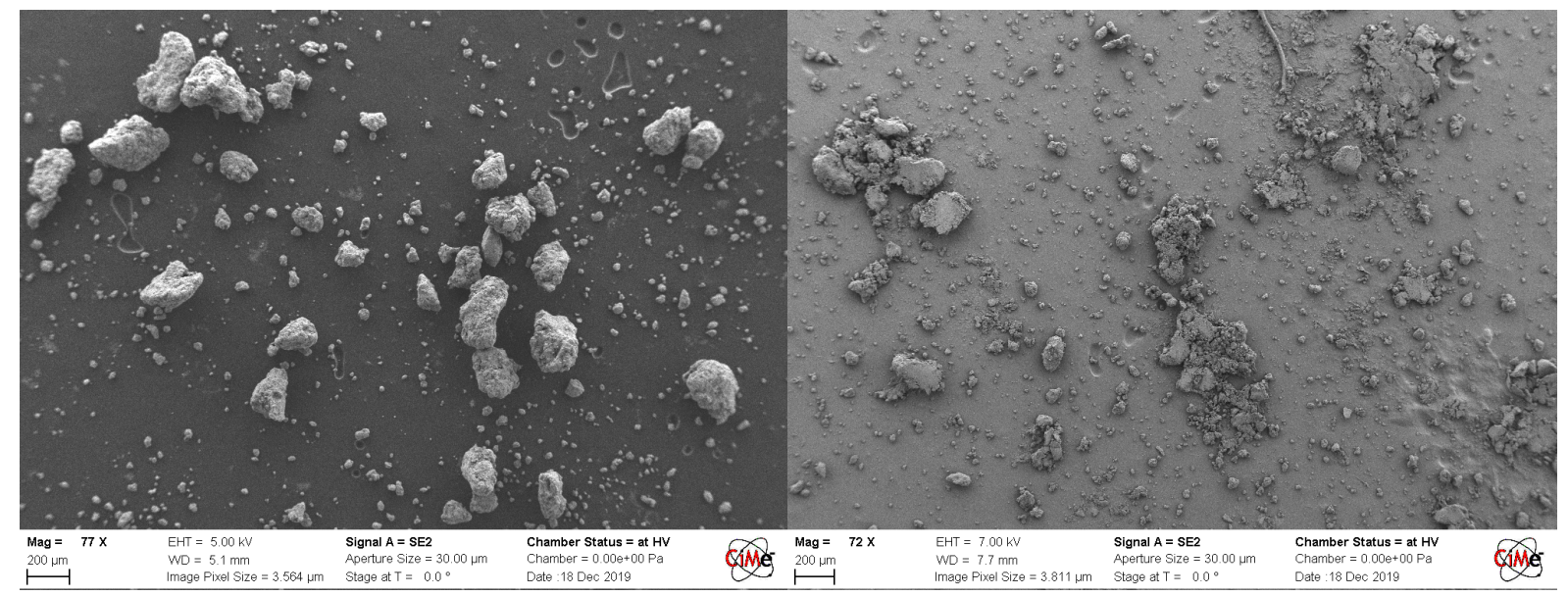

$\mathrm{Li}_{4} \mathrm{Ti}_{5} \mathrm{O}_{12}$ as received.

$\mathrm{Li}_{4} \mathrm{Ti}_{5} \mathrm{O}_{12}$ crushed by hand.

Figure S4. SEM images of the lithium titanate powders. 


\section{References}

1. Lelli, M.; Chaudhari, S. R.; Gajan, D.; Casano, G.; Rossini, A. J.; Ouari, O.; Tordo, P.; Lesage, A.; Emsley, L. Solid-State Dynamic Nuclear Polarization at 9.4 and $18.8 \mathrm{~T}$ from $100 \mathrm{~K}$ to Room Temperature. J. Am. Chem. Soc. 2015, 137, 14558-14561.

2. Dorrian, J. F.; Newnham, R. E. Refinement of the Structure of Li2TiO3. Mater. Res. Bull. 1969, 4, 179-183.

3. Deschanvres, A.; Raveau, B.; Sekkal, Z. Synthesis and Crystallographic Study of New Solid Solution of Spinel Li1+XTi2-XO4 Less Than or Equal to X Less Than or Equal to 0,333. Mater. Res. Bull. 1971, 6, 699-704.

4. Zhang, W.; Cory, D. G. First Direct Measurement of the Spin Diffusion Rate in a Homogenous Solid. Physical Review Letters 1998, 80, 1324--1327.

5. Khutsishvili, G. R. Spin Diffusion. Sov Phys Usp 1966, 8, 743-769.

6. Clough, S.; Gray, K. W. The Stochastic Theory of the Nuclear Magnetic Resonance Line in Rotating Solids. Proceedings of the Physical Society 1962, 79, 457.

7. Bjorgvinsdottir, S.; Walder, B. J.; Pinon, A. C.; Emsley, L. Bulk Nuclear Hyperpolarization of Inorganic Solids by Relay from the Surface. J. Am. Chem. Soc. 2018, 140, 7946-7951. 